\title{
Emotional processing following cortical and subcortical brain damage: contribution of the fronto-striatal circuitry
}

\author{
Caterina Breitenstein ${ }^{\mathrm{a}, \mathrm{b}, *}$, Irene Daum ${ }^{\mathrm{c}}$ \\ and Hermann Ackermann ${ }^{\mathrm{d}}$ \\ ${ }^{\mathrm{a}}$ Institute of Medical Psychology, University of \\ Tübingen, Germany \\ ${ }^{\mathrm{b}}$ Department of Neurology, University of Southern \\ California, Los Angeles, CA, USA \\ ${ }^{\mathrm{c}}$ Department of Psychology, Clinical \\ Neuropsychology, Ruhr-University Bochum, Germany \\ ${ }^{\mathrm{d}}$ Neurological Clinic, University of Tübingen, \\ Germany
}

Received 4 June 1997

Revised 19 February 1998

\begin{abstract}
The present study examined the differential contribution of cortical and subcortical brain structures in emotional processing by comparing patients with focal cortical lesions $(n=32)$ to those with primarily subcortical dysregulation of the basal ganglia (Parkinson's disease; $n=14)$. A standardized measure of emotional perception (Tübingen Affect Battery) was used. Only patients in the more advanced stages of Parkinson's disease and patients with focal damage to the (right) frontal lobe differed significantly from controls in both facial expression and affective prosody recognition. The findings imply involvement of the fronto-striatal circuitry in emotional processing.
\end{abstract}

Keywords: Facial expressions, affective prosody, right hemisphere dominance, Parkinson's disease

\section{Introduction}

Recent investigations with neurological patients have provided evidence of an involvement of neocortical brain areas in nonverbal ${ }^{1}$ communication of emo-

${ }^{*}$ Corresponding author: Dr. Caterina Breitenstein, Department of Neurology, University of Southern California, VA Outpatient Clinic (126), 351 East Temple Street, Los Angeles, CA 90012, USA. Tel.: +1 213 253-2677, ext. 4666; Fax: +1 213 253-5146; E-mail: breitens@hsc.usc.edu.

1 'Nonverbal' emotional processing refers to the perception/expression of emotions in vocal intonations, facial expressions, and gestures. tion. Research findings further suggest a dominant role of the right hemisphere in the decoding of AFFECTIVE PROSODY ${ }^{2}[7,27,33,43,56,57,58,69]$ as well as FACIAL EXPRESSIONS [7, 23, 25, 42]. The deficits observed in neurological patients with right hemisphere damage could neither be explained by a general impairment in processing visual-spatial, nonemotional facial or acoustic stimuli $[11,14,25]$ nor by a general lack of emotional comprehension [7]. The observed impairments have been interpreted with the destruction and/or disconnection of 'category-specific lexicalsemantic representations of nonverbal expressions' [7, p. 1125] in the right hemisphere, which may lead secondarily to a higher distractability for context information, e.g., the semantic content of sentences $[32,66]$.

The widely accepted notion of a general right hemisphere dominance in the identification of facial and vocal emotions was recently challenged. Several investigations during the last decade could not support a right hemisphere superiority for facial expressions [18, 26, 67, 74], affective prosody [18, 72], or linguistic prosody [31].

In order to resolve some of the uncertainty in the literature with respect to a right hemisphere dominance for emotional prosody processing (which is at least partially due to differences in study designs) Pell and Baum [51] incorporated different degrees of linguistic structure (speech-filtered/phonetic, nonsense/syntactic, semantically well-formed/semantic) into a single experimental design. Tasks involved discrimination and identification of linguistic and emotional prosodic stimuli. Overall, the main finding was

\footnotetext{
2 'Prosody' is defined as the speech rhythm, the pitch contour, and the accent patterns accompanying vocal utterances [45]. In addition to the discrimination of statement and question contours (linguistic prosody), there are intonation patterns differentiating emotional states of the speaker (affective or emotional prosody; [1]). Prosodic tasks usually involve either the discrimination of two sentences (same/different judgements) or the identification of the expressed emotion.
} 
that neither the patients with right (without neglect) nor left hemisphere damage were impaired compared to controls in discriminating or recognizing affective prosody on either task level, but that patients with leftsided damage showed deficits in semantically biasing tasks. The authors conclude that the results of previous studies reporting significant emotional prosodic deficits following right hemisphere damage are probably confounded by the co-existence of lasting visual neglect behavior in patient groups with temporoparietal lesions.

Attentional demand of the tasks used may be another intervening factor. For example, Schmitt et al. [61] tested patients with right and left hemisphere damage in a task which required subjects to simultaneously judge the facial expression, the emotional prosody, and the emotional meaning of videorecorded stimulus scenes. The authors intended to simulate naturally occurring social interactions, but the design of the task may have put an attentional over-demand on the reduced attentional resources of the patient groups, especially when the three channels of communication were conflicting.

Besides interhemispheric differences, a differential involvement of INTRAHEMISPHERIC brain areas in the PERCEPTION and PRODUCTION of emotion is still disputed. Ross [56] postulated the existence of an emotional processor in the right hemisphere that functions as an analog to the speech processor in the left hemisphere [28]. According to this theory, anterior brain structures are involved in expressive tasks, whereas posterior areas contribute to stimulus reception. More recent investigations differentiating between patient groups with anterior and posterior lesions of the right or left hemisphere failed to report significant differences between these groups [24]; for a summary, see [10]. One exception is the recent study by Hornak et al. [36] who reported significant group differences in the naming of facial expressions between patients with orbital or ventrolateral frontal damage and patients with lesions outside this area (dorsolateral frontal, temporal or parietal). The patient groups did not differ in a (nonstandardized) task which consisted of naming emotional human 'sounds'. In the latter task, both patients with orbital/ventrolateral frontal and non-ventral damage performed significantly inferior to control subjects. The authors explained their results in light of the direct anatomical projections from both visual and auditory temporal cortex areas to the orbitofrontal cortex $[6,46]$ which serve the function of associating sensory stimuli with reinforcing/punishing attributes.

Recently, there has been support for an important role of the BASAL GANGLIA in emotion processing. Cancelliere and Kertesz [18] concluded from their data that patients with cortical lesions who had additional damage to the basal ganglia and/or the anterior temporal lobes showed the most pronounced deficits in emotional judgements, independent of the lesion side. Further evidence is provided by studies describing prosodic and facial comprehension disorders in patients with PARKINSON'S DISEASE (PD), a neurological condition with primarily dysregulation of the basal ganglia. Scott et al. [62] reported reduced performance in identification of affective prosody and facial expressions in a group of patients with PD in (supposedly) more advanced stages of the disease, unfortunately using nonstandardized emotional test material. The performance of patients with PD in the earliest stage of the disease, however, did not differ from healthy normal control subjects in standardized emotional tasks [8]. In an attempt to integrate these controversial findings, Pell [50] presented 11 more advanced PD patients with a battery of emotional prosody tasks (using sentences with both semantically congruent and nonsense content). Overall, the performance of PD patients was significantly inferior to control subjects in the four identification tasks (84\% correct compared to $90 \%$ correct), indicating a degradation of prosodic functions but not a complete loss of prosodic knowledge [62]. Furthermore, Jacobs et al. [37] found significantly impaired performance in PD patients (also supposedly in more advanced stages) compared to control subjects in the discrimination of facial emotions and in tasks using emotional imagery. Dysfunction of the direct neuroanatomic connections between the ventral striatum and the limbic system [38] could explain the observed deficits of patients with PD in the processing of 'emotionally or motivationally powerful stimuli' [34, p. 87].

One further theory of emotional processing, the VALENCE HYPOTHESIS, postulates a dominance of the right hemisphere in the processing of negative emotions, whereas the left hemisphere is more involved in the comprehension of positive emotions (for a review, see [64]). The majority of studies with neurological patients, however, have not provided support for this differentiation (see [10]). Since most of these investigations used summary scores across all negative and positive emotions (e.g., pooled across anger, fear, sadness etc. for negative emotions), group dif- 
ferences in single emotional categories may have been overlooked. Recently, evidence for the role of the amygdala in recognizing SPECIFIC EMOTIONS signaling threat/arousal (see also [41]) has been provided by several single case-studies presenting patients with selective bilateral damage to the amygdala (Urbach-Wiethe disease, amygdalotomy, encephalitis). The patients presented with selective deficits for the recognition of FEARFUL (and to a lesser extent angry) facial expressions, but not for the naming of other basic emotions in facial expressions or for the identification of famous faces [2, 3]. In this context, it is important to note that patients with unilateral damage of the amygdala did not differ from the control group in recognition of any of the facial emotions [3], suggesting a bilateral processing of emotions at the medial temporal lobe level. Using a novel technique for interpolating pairs of facial emotion prototypes ('Identification of morphed facial expressions'), Calder et al. [17] reported impairments not only for the perception of fear, but also for the emotional category anger and to a lesser extent disgust in two other patients with bilateral damage to the amygdala (see also [76]). The same group described impaired recognition of frightened and angry intonations in spoken words [63] in one of the two patients. The patient was also impaired in other complex auditory perception tasks (e.g., perception of linguistic prosody), indicating that the patient's impairment was not entirely restricted to affective prosodic recognition.

Contradictory results come from a study by Hamann et al. [30], who did not report deficits in the identification of facial emotions in two patients with complete bilateral destruction of the amygdala. The differences between research findings may be due to patients' different ages at the onset of lesion. Contrary to the patients in the other investigations, the two patients in the study by Hamann et al. [30] suffered from lateacquired brain lesions and may have established alternative neural networks outside the amygdala, possibly in posterior cortical regions of the right hemisphere [4].

Another line of evidence for the so-called 'separate substrates hypothesis' [17] of different emotions comes from recent PET [47] and fMRI [53] studies in normal control subjects (reporting that fearful stimuli activated the amygdala and disgust stimuli the anterior insular cortex) as well as from preliminary reports of especially severe deficits in the recognition of facial and vocal DISGUST (and to a lesser extent fear) in patients with HUNTINGTON's DISEASE (HD, [65]) as well as in HD gene carriers [29]. Neocortical degenera- tion in patients with HD is widespread (involving both the basal ganglia as well as posterior cortex regions), making it difficult to relate the observed deficits in symptomatic patients with HD to a specific brain structure. Studies with HD gene carriers (i.e., clinically pre-symptomatic individuals) are therefore of particular interest with respect to neural substrates of emotion, because basal ganglia structures (caudate nucleus) are affected earliest by the neurodegeneration.

Furthermore, clinically significant disorders of emotional processing can be MODALITY-SPECIFIC (e.g., limited to facial or affective prosodic or gestural processing impairments) or generalized. So far, there is controversy in the literature about whether a central processor exists or whether the different modalities are processed independently. Bowers et al. [13] reported a double dissociation between identification of facial and affective prosodic stimuli in $22 \%$ of patients with right hemisphere damage and in $8 \%$ of patients with focal lesions of the left hemisphere, suggesting independent modality-specific processors. Evidence of different modalities for facial and affective prosodic perception comes from the study by Hornak et al. [36] who found dissociations between facial and vocal processing in all of their non-ventral damage patients, whereas eight of the 12 patients with orbital/ventrolateral frontal lesions were impaired in both modalities. Contradictory results were reported by Cancelliere and Kertesz [18], who classified $75 \%$ of the patients with right-sided lesions and $77.8 \%$ of the patients with damage to the left hemisphere as 'global aprosodic', with impairments in both facial and affective prosodic modalities. A problem with the latter study, however, is the minimal criterion for time since lesion (two weeks to three months). Observed deficits during this early stage might be due to nonspecific brain swelling [15], and patients might show complete or partial spontaneous recovery, especially of prosodic functions (e.g., [19]).

In summary, findings concerning affective perception in patients with cortical and/or subcortical dysfunctions remain divergent [39]. The discrepancy might be caused by inclusion of heterogenous patient samples with regard to intrahemispheric lesion site and time interval since brain damage. As many studies used nonstandardized, ad hoc constructed test materials of unknown reliability, it is unclear whether a single, homogeneous function, e.g., emotional processing, was measured. We are not aware of any study directly comparing the results of patients with unilateral focal cortical lesions to patients presenting with 
primarily subcortical dysregulation of the basal ganglia (e.g., patients with PD). Furthermore, recent investigations including patients with $\mathrm{PD}$ did not differentiate between patients in the earliest and more advanced stages of the disease, despite neuroanatomical considerations as well as research findings (see above) predicting differing results.

The main objective of the present study was to determine whether differential patterns of performance in the comprehension of linguistic/affective prosody and facial expressions can be demonstrated in patients with focal cortical lesions (right versus left, anterior versus posterior) and primarily subcortical dysregulation (e.g., patients with PD) using standardized test material. A German version [16] of the Florida Affect Battery - Revised [12] was developed and used to test these patient groups systematically. The inclusion of patients with PD was based on the theoretical assumption that in the earliest stage of the disease the pathophysiological processes are generally limited to subcortical structures (substantia nigra and basal ganglia), whereas during the course of the disease functionally related neuroanatomical structures (especially the frontal lobes) are involved [49]. This research design therefore allows some degree of estimation of differential contributions of cortical and subcortical brain structures in affective processing. For the patients with $\mathrm{PD}$, it was hypothesized that patients in the earliest stage of the disease would match the performance of normal control subjects, whereas the results of patients in more advanced stages might be more similar to those of patients with frontal lesions.

Also of special interest was the association between performance in recognition of facial expressions and that of performance in affective prosody (both modalities assessed in the same study).

In the light of recent developments on neural differentiation of specific emotions, we also wanted to test whether observed deficits are limited to SPECIFIC EMOTIONS, as recently reported for patients with HD/bilateral amygdala lesions [2, 3, 17, 29].

\section{Methods}

\subsection{Subjects}

Thirty-two patients with focal cerebral lesions involving the cortex, 14 non-demented patients with PD and two groups of healthy controls (HC) matched to the patients for age, sex, and IQ took part in the follow- ing study. All subjects were right-handed (Edinburgh Handedness Inventory, [48]).

The inclusion of separate control groups for the patients with cortical lesions $(n=10)$ and the patients with PD $(n=12)$ was necessary because PD patients were generally older (about 10 years) than the other patient groups. Age might be an intervening factor in affective processing in clinical groups [68] and should be controlled for. Although the majority of studies failed to report sex differences (e.g., [10]) or correlations with intellectual functioning, the patient groups and $\mathrm{HC}$ were matched for these variables.

Exclusion criteria for the $\mathrm{HC}$ were (a) a history of psychiatric and/or neurological diseases, and (b) the intake of medication affecting the central nervous system at the time of testing. HC were recruited through advertisements in public institutions and university buildings.

\subsubsection{Patients with cortical lesions}

Of the 32 patients, 16 had lesions confined to the right hemisphere $(\mathrm{R})$, and 16 patients had suffered damage to the left hemisphere (L). In each of these two subgroups, eight patients had focal lesions of the anterior (A) lobes, and eight patients had lesions limited to posterior $(\mathrm{P})$ brain structures. Etiologies comprised cerebral vascular accidents (stroke), brain tumor removal, contusions, temporal lobe resection because of medically refractory epileptic seizures, and gunshot wound. The patients were recruited from the outpatient clinic of the Department of Neurology, University of Tübingen, Germany. All lesion locations were documented by CT- and/or MRI-scans. More detailed information on the extent of the lesion, e.g., more localized sites within the frontal lobe, were not available. In all cases, however, the lesion did not extend beyond the anterior or posterior cortex and was restricted to one hemisphere. Thirteen patients $(40.6 \%)$ were taking anticonvulsive medication at the time of testing (phenytoin, carbamazepine, valproic acid) with patient groups not differing in the distribution of medication $\left(\chi_{(12)}^{2}=9.45, p=0.66\right)$. The characteristics of the four patient groups and their matched $\mathrm{HC}$ are provided in Tables 1 and 2.

Inclusion criteria for the study were: (a) an interval of at least 12 weeks and at maximum eight years since occurrence of the lesion; (b) no clinically significant aphasic symptoms; (c) no history of psychiatric disorders; and (d) no signs of dementia or neglect. 
Table 1

Clinical information (patients with cortical lesions)

\begin{tabular}{|c|c|c|c|}
\hline Case no. & Interval $^{a}$ & Etiology $\mathrm{y}^{b}$ & Lesion site \\
\hline \multicolumn{4}{|c|}{ Right anterior damage } \\
\hline 01 & 66 & REF & fronto-lateral \\
\hline 02 & 03 & CVA & frontal (anterior cerebral artery) \\
\hline 03 & 06 & BTR (astrocytoma) & frontal \\
\hline 04 & 25 & BTR (menigeoma) & fronto-lateral \\
\hline 05 & 15 & CVA & fronto-lateral; involvement of basal ganglia \\
\hline 06 & 17 & CVA & frontal (rostral media artery) \\
\hline 07 & 12 & $\mathrm{CON}$ & frontal \\
\hline 08 & 96 & BTR (oligoastrocytoma) & frontal \\
\hline \multicolumn{4}{|c|}{ Right posterior damage } \\
\hline 01 & 07 & GSW & temporo-occipital \\
\hline 02 & 96 & BTR (melanoma) & parieto-occipital \\
\hline 03 & 19 & BTR (menigeoma) & temporo-parietal; involvement of basal ganglia \\
\hline 04 & 25 & BTR (astrocytoma) & parietal \\
\hline 05 & 05 & BTR (astrocytoma) & temporal \\
\hline 06 & 12 & CVA & temporo-parieto-occipital \\
\hline 07 & 24 & $\mathrm{CON}$ & temporal \\
\hline 08 & 22 & $\mathrm{CON}$ & temporal \\
\hline \multicolumn{4}{|c|}{ Left anterior damage } \\
\hline 01 & 15 & $\mathrm{CON}$ & frontal \\
\hline 02 & 33 & $\mathrm{CON}$ & ventral frontal \\
\hline 03 & 14 & BTR (glioblastoma) & frontal \\
\hline 04 & 23 & $\mathrm{CON}$ & frontal \\
\hline 05 & 84 & BTR (oligoastrocytoma) & frontal \\
\hline 06 & 17 & CVA & rostral frontal \\
\hline 07 & 75 & BTR (oligodendroglioma) & frontal \\
\hline 08 & 22 & BTR (mixed glioma) & frontal \\
\hline \multicolumn{4}{|c|}{ Left posterior damage } \\
\hline 01 & 04 & $\mathrm{CON}$ & temporo-occipital \\
\hline 02 & 15 & BTR (gioblastoma) & parieto-occipital \\
\hline 03 & 91 & BTR (astrocytoma) & temporo-occipital; involvement of the basal ganglia \\
\hline 04 & 60 & CVA & parietal \\
\hline 05 & 03 & $\mathrm{CON}$ & parietal \\
\hline 06 & 27 & $\mathrm{CON}$ & temporo-parietal \\
\hline 07 & 60 & BTR (oligoastrocytoma) & temporal \\
\hline 08 & 15 & CVA & temporo-parietal \\
\hline
\end{tabular}

${ }^{a}$ Time since lesion (in months).

${ }^{b} \mathrm{REF}=$ removal of epileptic focus; $\mathrm{BTR}=$ brain tumor removal; $\mathrm{CVA}=$ cerebrovascular accident $\mathrm{CON}=\mathrm{contusion}$; GSW = gunshot wound.

\subsubsection{Patients with $P D$}

Seven patients with PD fulfilled the criteria for stage I (unilateral symptoms), and seven patients were in stage II (bilateral symptoms) according to the Hoehn and Yahr [35] classification system for severity of motor symptoms. All patients were medicated at the time of testing (a standard combination of levodopa, D2-agonist, and MAO-B-inhibitor), none of the patients had undergone surgical treatment for PD (see Table 3 for patient characteristics). The patients were recruited from the outpatient clinic of the Department of Neurology, University of Tübingen, Germany.

\subsection{Materials}

\subsubsection{Neuropsychological background screening}

A short neuropsychological screening battery was administered to all subjects to control for general performance deficits which might influence the affective processing test performance. Basic INTELLECTUAL FUNCTIONING (subtests 'Similarities' and 'Picture completion' of the German version of the reduced Wechsler scale; WIP [21]), ATTENTION SPAN ('digit span' [73]) and MOOD ('Bond-Lader Visual Analogue Scales' [9]; German version [22]) were assessed.

Hearing abilities were tested in a short audiometric examination: inclusion criteria for the following study 
Table 2

Demographic and neuropsychological data (patients with cortical lesions and healthy controls)

\begin{tabular}{|c|c|c|c|c|c|}
\hline Variable & RA & LA & $\mathrm{RP}$ & LP & $\mathrm{HC}$ \\
\hline sample size $(n)$ & 8 & 8 & 8 & 8 & 10 \\
\hline $\begin{array}{l}\text { sex } \\
\text { female/male }\end{array}$ & $4 / 4$ & $3 / 5$ & $5 / 3$ & $2 / 6$ & $6 / 4$ \\
\hline $\begin{array}{l}\text { handedness } \\
\text { unilateral right } \\
\text { ambidextrous }\end{array}$ & $\begin{array}{l}5 \\
3\end{array}$ & $\begin{array}{l}8 \\
0\end{array}$ & $\begin{array}{l}7 \\
1\end{array}$ & $\begin{array}{l}7 \\
1\end{array}$ & $\begin{array}{r}10 \\
0\end{array}$ \\
\hline $\begin{array}{l}\text { duration since le } \\
\text { (in months) } \\
\text { M } \\
\text { SD } \\
\text { Range }\end{array}$ & $\begin{array}{r}28.9 \\
33.5 \\
3-96\end{array}$ & $\begin{array}{r}35.4 \\
28.0 \\
14-84\end{array}$ & $\begin{array}{r}26.3 \\
29.2 \\
5-96\end{array}$ & $\begin{array}{r}34.4 \\
32.1 \\
3-91\end{array}$ & \\
\hline $\begin{array}{l}\text { age in years } \\
\mathrm{M} \\
\mathrm{SD} \\
\text { Range }\end{array}$ & $\begin{array}{r}45.8 \\
19.3 \\
22-73\end{array}$ & $\begin{array}{r}40.6 \\
10.1 \\
18-53\end{array}$ & $\begin{array}{r}48.4 \\
11.9 \\
33-69\end{array}$ & $\begin{array}{r}41.8 \\
14.1 \\
26-63\end{array}$ & $\begin{array}{r}44.4 \\
11.5 \\
27-70\end{array}$ \\
\hline $\begin{array}{l}\text { intelligence verb } \\
\mathrm{M} \\
\mathrm{SD}\end{array}$ & $\begin{array}{r}113.5 \\
11.2\end{array}$ & $\begin{array}{r}102.5 \\
10.8\end{array}$ & $\begin{array}{r}110.5 \\
15.6\end{array}$ & $\begin{array}{r}107.9 \\
8.2\end{array}$ & $\begin{array}{r}114.7 \\
16.9\end{array}$ \\
\hline $\begin{array}{l}\text { performance } \\
\text { M } \\
\text { SD }\end{array}$ & $\begin{array}{r}109.3 \\
10.9\end{array}$ & $\begin{array}{r}109.8 \\
11.4\end{array}$ & $\begin{array}{r}101.5 \\
8.8\end{array}$ & $\begin{array}{r}110.9 \\
14.0\end{array}$ & $\begin{array}{r}109.3 \\
16.5\end{array}$ \\
\hline $\begin{array}{l}\text { attention span } \\
\text { forward }\end{array}$ & & & & & \\
\hline $\begin{array}{l}\text { M } \\
\text { SD } \\
\text { backward }\end{array}$ & $\begin{array}{l}6.1 \\
0.8\end{array}$ & $\begin{array}{l}6.9 \\
1.0\end{array}$ & $\begin{array}{l}5.9 \\
1.0\end{array}$ & $\begin{array}{l}5.5 \\
0.8\end{array}$ & $\begin{array}{l}6.5 \\
1.3\end{array}$ \\
\hline $\begin{array}{l}\mathrm{M} \\
\mathrm{SD}\end{array}$ & $\begin{array}{l}4.8 \\
1.3\end{array}$ & $\begin{array}{l}4.5 \\
0.8\end{array}$ & $\begin{array}{l}4.8 \\
1.5\end{array}$ & $\begin{array}{l}4.3 \\
1.7\end{array}$ & $\begin{array}{l}5.6 \\
1.2\end{array}$ \\
\hline $\begin{array}{l}\operatorname{mood}^{a} \\
\mathrm{M} \\
\mathrm{SD}\end{array}$ & $\begin{array}{l}40.4 \\
18.8\end{array}$ & $\begin{array}{l}30.8 \\
11.3\end{array}$ & $\begin{array}{l}29.4 \\
10.9\end{array}$ & $\begin{array}{r}40.3 \\
9.6\end{array}$ & $\begin{array}{l}31.1 \\
13.0\end{array}$ \\
\hline
\end{tabular}

$\mathrm{RA}=$ patients with right anterior damage; LA = patients with left anterior damage; $\mathrm{RP}=$ patients with right posterior damage; $\mathrm{LP}$ $=$ patients with left posterior damage; $\mathrm{HC}=$ healthy controls; $n=$ number; $\mathrm{M}=$ mean; $\mathrm{SD}=$ standard deviation.

${ }^{a}$ Higher scores reflect more depressed mood.

were that all presented frequencies $(500 \mathrm{~Hz}$ to $8000 \mathrm{~Hz}$ tones) had to be identified with a maximum sound pressure level of $30 \mathrm{~dB}$.

\subsubsection{Affective stimuli}

A highly reliable German version of the 'Florida Affect Battery - Revised' [12] was used to examine the nature of the perceptual affective deficits in the patient groups ('Tübingen Affect Battery': internal consistency by Cronbach's Alpha $=0.97$ for the complete battery, with Cronbach's Alpha ranging between 0.86 and 0.94 for the three parts of the battery [16]). A detailed description of the subtests as well as information about test construction is provided elsewhere (En-
Table 3

Demographic and neuropsychological data (patients with Parkinson's disease and healthy controls)

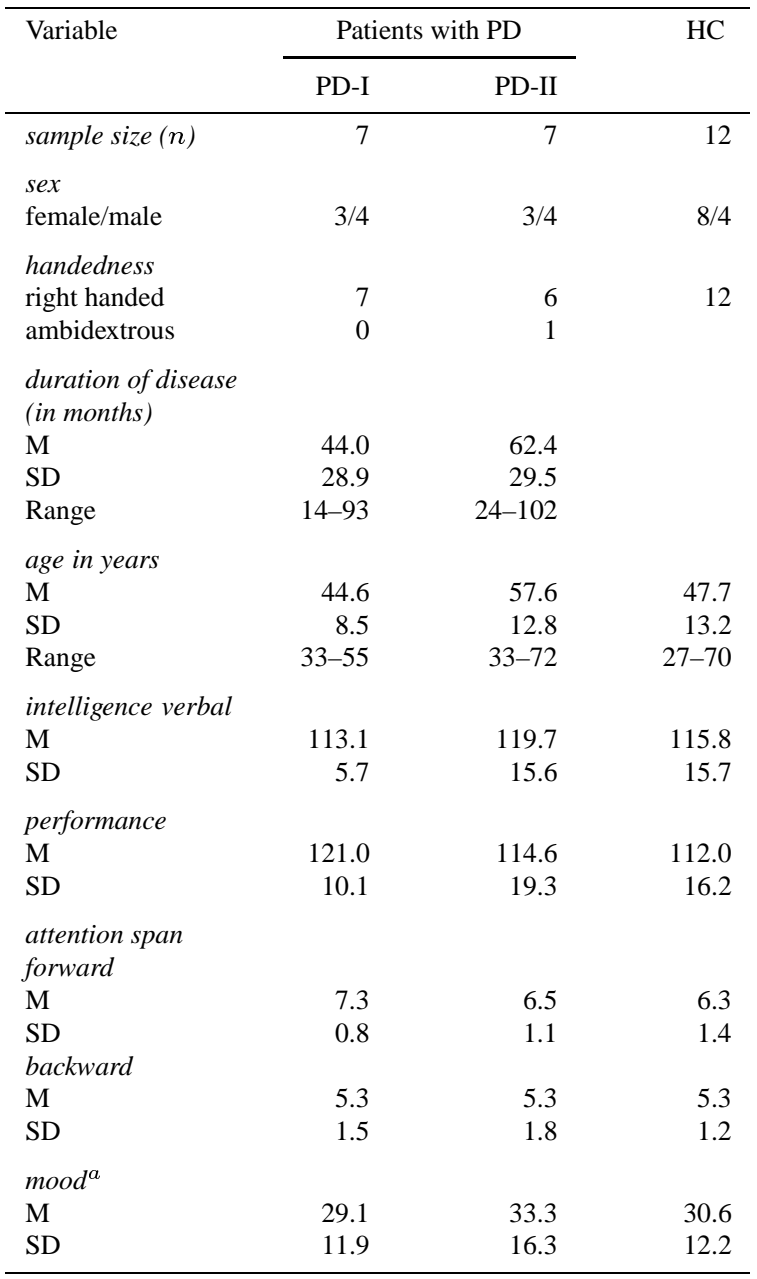

$\mathrm{PD}=$ Parkinson's disease $; \mathrm{PD}-\mathrm{I}=$ patients in the early stage; $\mathrm{PD}-\mathrm{II}=$ patients in more advanced stage; $\mathrm{HC}=$ healthy controls; $n$ = number; $\mathrm{M}=$ mean; $\mathrm{SD}=$ standard deviation.

${ }^{a}$ Higher scores reflect more depressed mood.

glish version [7]; German version [16]). The battery includes ten subtests (see Table 4): five subtests require discrimination, naming, pointing to, or matching of FACIAL STIMULI; in three subtests the subjects are asked to discriminate or name LINGUISTIC (1 subtest) and AFFECTIVE PROSODIC (2 subtests) sentences; in the remaining two subtests the subjects are instructed to MATCH a facial expression to one of three affective prosodic sentences or vice versa (crossmodal matching). Every subtest is preceded by several practice items to ensure that the task was understood. Both facial and affective prosodic stimuli depicted one of five different basic emotional categories: happiness, anger, 


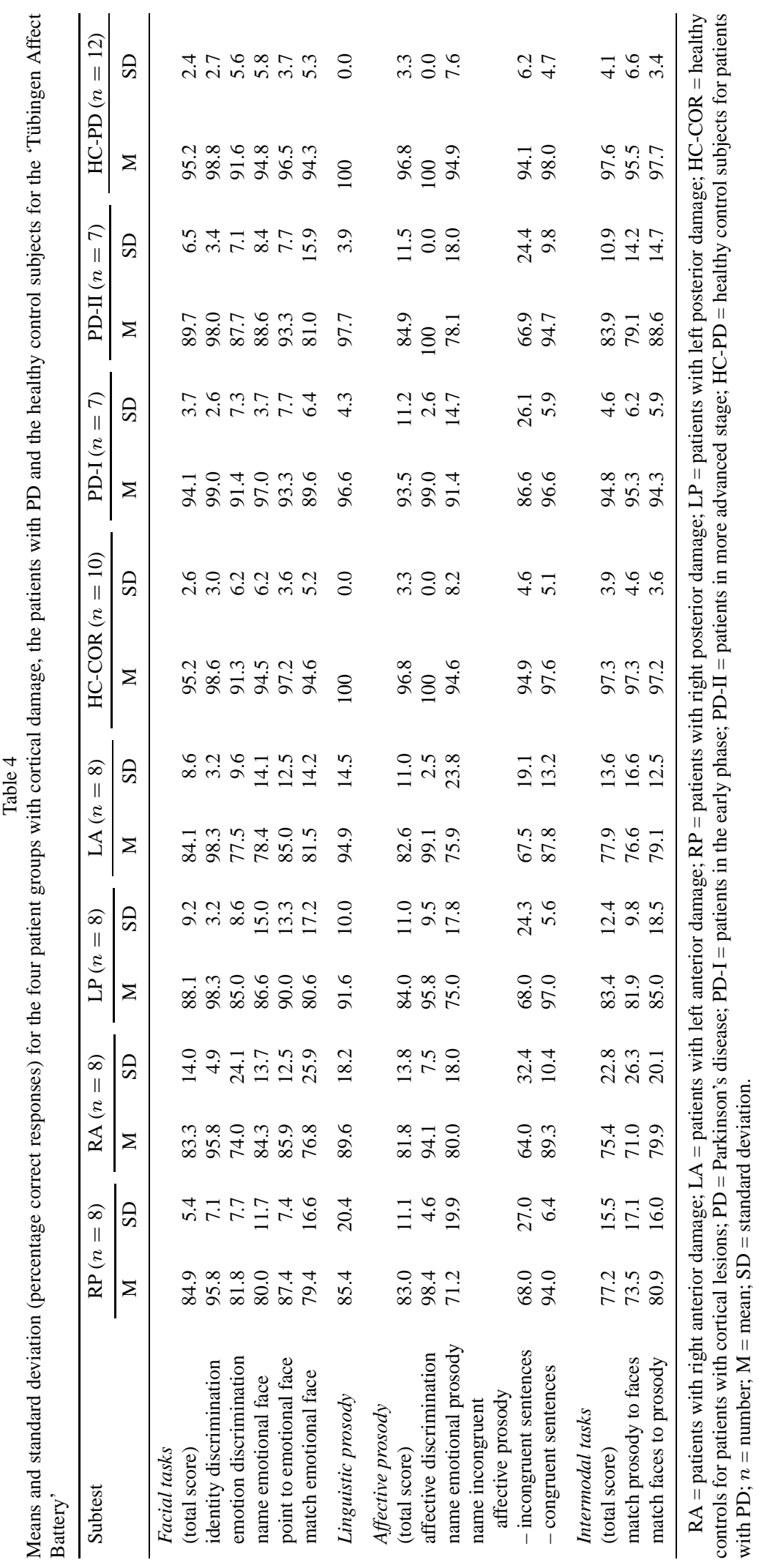


sadness, fear, and neutral expression. Responses could be made in either verbal or nonverbal (pointing to the emotion word on a vertically-arrayed multiple choice display of five emotion words) manner.

For the German version, all sentences of the Florida Affect Battery [12] were translated to match the English original as closely as possible with regard to content and syllable length. A professional actress was instructed to intonate these sentences with the six different emotions (80 sentences with 16 different emotional or emotional neutral meanings) or to speak them as questions (5 sentences). All sentences were recorded (in multiple repetitions) using digital equipment, and were processed with a sampling rate of $25 \mathrm{kHz}$ ('Computerized Speechlab 4300'; Kay Elemetrics Corp., USA). The authors chose the most characteristic presentation with respect to the intended emotion from the multiple versions of each sentence. The selected items were recorded on an audiotape.

In the next step, all 60 facial stimuli (originals taken from the English version) as well as the 85 prosodic sentences were given to 100 normal control subjects (50 women), and the results subjected to an item analysis. Items with negative or near-zero item-whole correlations were excluded. This resulted in a decreased number of items in the German test battery compared with the English version (15 facial identity stimuli, 30 facial expressions, 45 prosodic sentences). Item difficulties ranged between 68 and $100 \%$, a ceiling effect was expected in this sample of normal controls (see [12])

\subsection{Procedure}

After the subjects had provided informed consent, the neuropsychological screening battery was administered (about $20 \mathrm{~min}$ ), followed by presentation of the 'Tübingen Affect Battery' (about $60 \mathrm{~min}$ ) in a quiet room. The audiotaped recordings were played on a portable tape player through stereo headphones. The tape was paused when the subject did not respond in the $4 \mathrm{sec}$ interval between stimuli. Both a total score (mean score for all 10 subtests) and sub-scores for each of the four parts (facial expression, linguistic prosody, affective prosody, matching) were calculated for each subject. Travel expenses were reimbursed (DM 30,-).

\subsection{Data analysis}

All scores (percentage correct responses) were analyzed using one-way or two-way analyses of variance (ANOVA). For post hoc comparisons of paired groups, Tukey's HSD tests were performed.

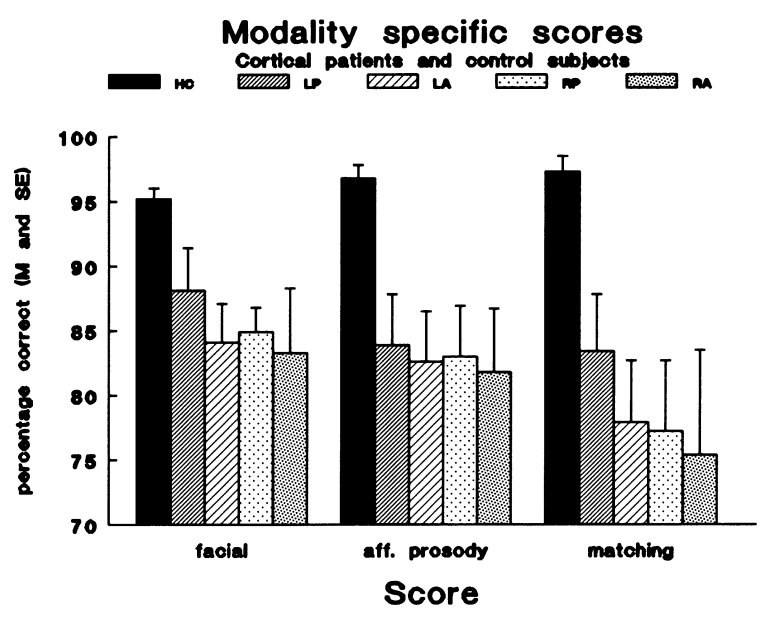

Fig. 1. Percentage correct (mean and standard error) for the modality-specific subscores (facial expressions, affective prosody, matching) of the different cortical patient groups $(\mathrm{RA}=$ patients with right anterior damage; $\mathrm{RP}=$ patients with right posterior damage; $\mathrm{LA}=$ patients with left anterior damage; $\mathrm{LP}=$ patients with left posterior damage) and healthy controls (HC).

\section{Results}

\subsection{Patients with cortical lesions}

The four patient groups and HC did not differ in the distribution of SEX or HANDEDNESS, nor in AGE, INTELLECTUAL FUNCTIONING, ATTENTION SPAN, or in subjective MOOD (all $p>0.10$ ). TIME SINCE LESION $(F(3,28)=0.16, p=0.92)$ or distribution of LESION ETIOLOGY $\left(\chi_{(12)}^{2}=9.29, p=0.69\right)$ did not differ in the four patient groups.

Group comparisons for the total score and modalityspecific scores. Mean and standard deviations for all scores and all groups are displayed in Table 4. ANOVAs revealed significant group differences for the TOTAL score $(F(4,37)=3.61, p=0.01)$ as well as for three MODALITY-SPECIFIC (facial expressions, affective prosody, matching) subscores (all $F(4,37)>2.98$, $p<0.03$; see Fig. 1), but not for linguistic prosody $(F(4,37)=1.35, p=0.27)$. Post hoc analyses (Tukey tests) showed significantly reduced TOTAL performance and significantly lower scores in the MATCHING subscore for both patient groups with right hemisphere lesions (RA, RP) compared to HC (all $p<0.05$ ). The RA patient group scored significantly lower than the HC group for FACIAL EXPRESSIONS and AFFECTIVE PROSODY (both $p<0.05$ ), patients in the LA group differed from $\mathrm{HC}$ in the AFFECTIVE PROSODY subscore $(p=0.047)$. The patient groups did not differ from each other in any of the scores (all $p>0.81$ ). 
'Double dissociation'. To test the hypothesis that a central processor exists for both modalities (facial expression versus affective prosody), a criterion for 'double dissociation' was developed: test performance for the patient had to be within the range of the HC group in one modality and below the range of the $\mathrm{HC}$ in the other modality. Additionally, a critical difference between modality-specific subscores had to be exceeded, e.g., the critical difference had to lie above the greatest difference of the HC (critical difference greater than $4.6 \%$ ). Results showed that 10 of the 32 patients fulfilled this criterion: six patients presented with a modality-specific impairment for affective prosody (3 LP, 1 LA, 1 RP, 1 RA), and four patients showed specific impairments for facial expressions (2 LA, $2 \mathrm{RP}$ ). However, 17 patients showed decreased performance in both modalities ('global affective agnosics'), suggesting dependent processing of both modalities.

Valence hypothesis. ${ }^{3}$ An ANOVA with the betweengroup factor 'group' and the repeated factor 'valence' (angry, happy, sad, frightened, neutral) was conducted (separately for facial expression, affective prosody, and matching scores) to explore whether lesion location is related to performance in specific emotions. A significant interaction of the two factors emerged for facial expressions and affective prosody (both $F(16,148)>2.00, p \leq 0.02)$, but not for the matching condition. The results are presented in Fig. 2.

For FACIAL EXPRESSIONS, significant group differences were found for the angry category only $(F(4,37)=5.15, p=0.002)$. Group differences for frightened facial expressions approached significance $(F(4,37)=2.28, p=0.08)$. Post hoc analyses (Tukey tests) revealed significantly lower scores of the LA and the RP patient groups compared to $\mathrm{HC}$ in the anger category (both paired comparisons: $p<0.01$ ), but no significant group differences between any of the four patient groups. It should be noted that the identification of angry faces was among the most difficult to recognize emotional category for all patient groups (see Fig. 2).

The significant interaction of 'valence $\mathrm{x}$ group' for the AFFECTIVE PROSODY domain was due to significant group differences in the identification of sad and fright-

${ }^{3}$ The subtests identity and emotion discrimination (facial tasks) as well as affective discrimination (affective prosody tasks) were excluded from valence analyses since findings in patients with cortical lesions indicate that auditory recognition and discrimination may be separate abilities $[70,71]$

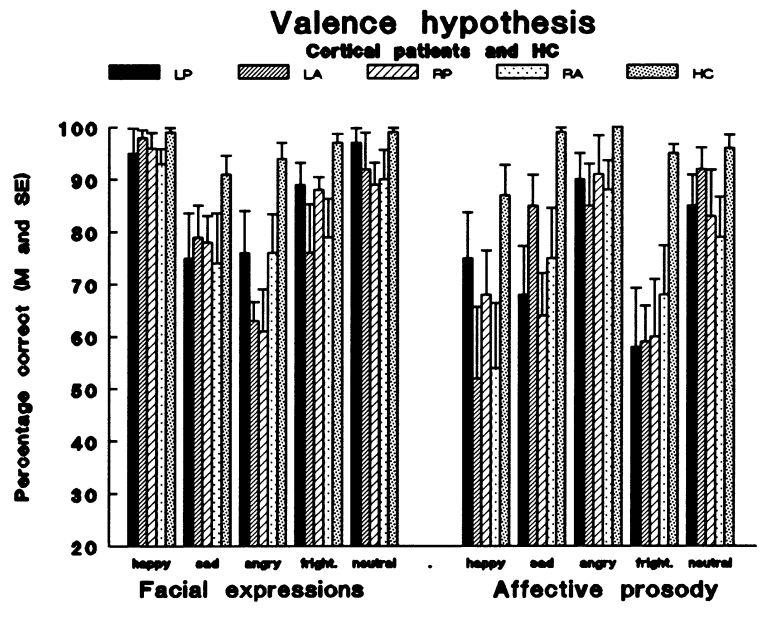

Fig. 2. Percentage correct (mean and standard error) for single emotional categories in facial expressions and affective prosody subtests of the different patient groups and healthy controls (RA $=$ patients with right anterior damage; $\mathrm{RP}=$ patients with right posterior damage; $\mathrm{LA}=$ patients with left anterior damage; $\mathrm{LP}=$ patients with left posterior damage; $\mathrm{HC}=$ healthy controls; fright. = frightened).

ened intonations (both $F(4,37)>4.00, p<0.01$ ), group differences for happy intonations approached significance $(F(4,37)=2.41, p=0.07)$. Whereas both patient groups with posterior lesions (LP, RP) achieved lower sad scores than the HC group (Tukey tests: both $p \leq 0.02$ ), scores for the frightened category were significantly reduced for three of the patient groups (LP, LA, RP) compared to the HC group (Tukey tests: all $p \leq 0.03)$. No significant group differences emerged between any of the four patient groups. As can be seen in Fig. 2, sad and frightened intonations were not the most difficult to recognize emotional categories. The patients' deficit may indicate a failure to process timing information which is the most characteristic acoustic component for both sad and frightened intonations (see Discussion).

Etiology of lesion. One possible explanation for the divergence of the present results from those of other research groups (e.g., [7]) could be the heterogeneous lesion etiologies in the present sample. To examine this possibility, the performance of the three most prominent etiological groups (cerebrovascular accident, contusion, brain tumor removal) was compared. ANOVAs revealed significant main effects for both total and composite test scores (all $F(3,36)>8.26, p<0.001)$. Paired comparisons (Tukey tests) showed that patients with CEREBROVASCULAR ACCIDENTS presented with the lowest performance in both total and subtest scores and differed sig- 
nificantly from the HC group (all $p<0.001$ ) as well as from patients with brain tumor removal (all scores: all $p<0.02$ ) or contusion (total score: $p=0.003$; affective prosody/matching: both $p<0.01$ ). Patients following brain tumor removal scored significantly lower than the HC group in both total score $(p=0.02)$ and affective prosody- or matching-subscores (both $p<0.02)$. In summary, patients with cerebrovascular accidents showed the poorest performance.

\subsection{Patients with $P D$}

The two patient groups (PD-I and PD-II) and their $\mathrm{HC}$ did not differ in distribution of SEX or HANDEDNESS, in INTELLECTUAL FUNCTIONING, MOOD, ATTENTION SPAN or AGE measures (all $p>0.12$ ). Patients in the earliest and more advanced stages of the disease were not significantly different with regard to DURATION OF DISEASE $(t(12)=-1.18, p=0.26)$.

Group comparisons for the total score and modalityspecific scores. ANOVAs revealed significant group differences for both the TOTAL score and modality (FACIAL EXPRESSIONS, AFFECTIVE PROSODY, MATCHING) subscores (all $F(2.23)>4.00, p<0.03$ ), but not for the linguistic prosody subscore. Paired group comparisons using Tukey's HSD tests showed that PD-II patients scored significantly lower in all subtests (except linguistic prosody) compared to HC (all $p<0.03$ ) and also performed significantly worse than the PD-I group in the matching task $(p=0.02)$. PD-I patients did not differ from $\mathrm{HC}$ in any of the measures (see Table 4 for means and standard deviations of all subtests).

Valence hypothesis. A repeated measures ANOVA with 'group' (PD-I, PD-II, NC) as between-group and 'valence' (angry, happy, sad, frightened, neutral) as within-group factors revealed a significant two-way interaction for AFFECTIVE PROSODY $(F(8,92)=2.10$, $p<0.05$; see Fig. 3), but not for the other modalities (facial expressions, matching). The interaction could be explained by group differences for angry and frightened intonations (both $F(2,23)>6.60$, $p<0.01)$. However, group differences for happy and sad prosody also approached significance (happy: $F(2,23)=3.55, p=0.05$; sad: $F(2,23)=3.24$, $p=0.06)$. Post hoc analyses (Tukey's HSD test) showed significantly reduced scores of PD-II patients compared to $\mathrm{HC}$ in both the angry and the frightened category (both $p \leq 0.01$ ). For angry prosodic utterances, PD-II patients also scored significantly lower

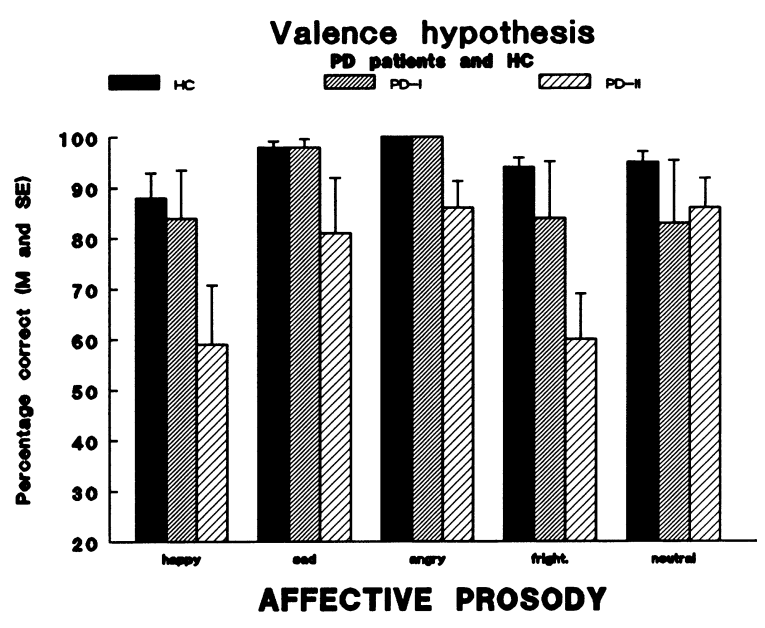

Fig. 3. Figure 3: Percentage correct (mean and standard error) for single emotional categories in the affective prosody subtests of the PD patient groups and healthy controls (PD - I=patients with PD in the early phase; $\mathrm{PD}-\mathrm{II}=$ patients with $\mathrm{PD}$ in more advanced stage; $\mathrm{HC}=$ healthy controls; fright. $=$ frightened).

than the PD-I patients (Tukey test: $p=0.003$ ). None of the other paired comparisons achieved significance. Recognition of angry intonations was at ceiling level in the HC group and in the PD-I group. The deficit observed in PD-II patients can thus not be explained by increased item difficulty. The deficit in recognizing angry and frightened tones of voice therefore seems to be idiosyncratic for the PD-II patients and may be related to a failure in processing vocal cues of arousal which is the shared acoustic component of these emotions (see Discussion).

\section{Discussion}

The main aim of the present study was to determine the differential contribution of cortical and subcortical brain structures in emotional processing by comparing patients with focal cerebral lesions and patients with primarily subcortical dysregulation of the basal ganglia (patients with PD). It was assumed that patients with PD with bilateral symptoms would perform similar to patients with focal frontal damage. Before moving on to a general discussion of the results, we will first summarize the main findings for the different patient groups.

Patients with cortical lesions. Results show differential impairment of the patients with cortical lesions compared to $\mathrm{HC}$, with the individual patient groups not significantly differing from one other. Whereas pa- 
tients with damage to either anterior or posterior parts of the right hemisphere presented with deficits in both total test score as well as in the intermodal matching subscore compared to $\mathrm{HC}$, only patients with right anterior lesions were impaired in the perception of facial expressions compared to HC. The results therefore support an overall RIGHT HEMISPHERE DOMINANCE in the processing of emotional stimulus material. For the affective prosody subscore, however, patients with anterior damage showed the lowest scores, independent of lesion side.

With respect to INTRAHEMISPHERIC LESION site, Ross' assumption of the dominance of the posterior right hemisphere in emotional perception [56] cannot be maintained. Patients with anterior and posterior lesions did not differ and patients with anterior damage showed the strongest impairments in both facial and prosodic emotional recognition, The results for the different etiological groups (cerebrovascular accident, brain tumor removal, contusion) rather suggest an intervening effect of lesion etiology: patients with cerebrovascular accidents showed the lowest test scores. This might be due to the more extensive lesions caused by ischemia compared to brain tumor removal or contusion. Further research should continue to investigate the 'etiology hypothesis'.

The present study also aimed to investigate whether the recognition of facial expressions and affective prosody are dependent or MODALITY-SPECIFIC. Ten of the 32 cortical patients showed a 'double dissociation' of facial and affective prosodic impairments which was, however, not clearly related to lesion site. Further interpretation of this result with regard to distinct processors for facial and affective prosodic perception is therefore not possible. Furthermore, the means of all four patient groups were similar to each other and were lower than those of the HC. One possible explanation could be that brain damage per se, independent of lesion site or side, affects emotional perception.

No significant group differences were found for the linguistic prosody subscore. The finding supports the assumption of SEPARATE CORTICAL MODULES FOR LINGUISTIC AND EMOTIONAL PROSODIC FUNCTIONS [52] and indicates that our patients did not present with a general impairment of processing complex auditory signals.

Noteworthy results emerged from the ANALYSES OF SPECIFIC EMOTIONS, indicating that the recognition of angry (and to a lesser extent frightened) FACIAL EXPRESSIONS were most affected in the cortical patients. The impairments were, however, not distinctly related to lesion site and are at variance with the findings by Adolphs et al. [4] that patients with damage to the left hemisphere perform within the normal range for all emotions. Our findings indicate that patients with cortical lesions were especially impaired with respect to facial emotions that are related to arousal and threat and did not show any deficits for happy facial expressions. Further interpretation of our findings is limited by the factor that intrahemispheric lesions of our patient samples were quite extensive and more detailed analysis of the locus of the damage was not possible. For AFFECTIVE PROSODY, both posterior groups presented with impaired recognition of sad intonations compared to $\mathrm{HC}$ and all patient groups (except the RA group) achieved lower scores for frightened prosody than the HC group. Different emotions can be described by different sets of acoustic parameters, with speech rate and pitch exerting the strongest effect on listeners' judgements $[59,60]$. In the temporal domain, a slow speech rate is perceived as sad and a fast rate as frightened or happy. The specific pattern of deficits thus indicates that the patients may fail to appropriately process timing information in the speech signals. Future studies should address this issue, for example, by systematically varying temporal information in prosodic stimuli.

Patients with PD. A differential pattern of impairment could be found for PD-patients with uni- and bilateral motor symptoms. Patients in the more advanced stage of the disease performed worse in both total test score as well as in the modality-specific subscores (FACIAL EXPRESSIONS, AFFECTIVE PROSODY, MATCHING) than the HC. Furthermore, in the matching subtest, which requires the integration of two different modalities (visual, acoustic), patients in more advanced stages were significantly more impaired than patients in the early stage. Patients with unilateral symptoms did not differ in any of the scores from the HC group, and their scores ranged between those of the patients in more advanced stages and the matched $\mathrm{HC}$.

With respect to SINGLE EMOTIONS, a differential deficit pattern was only observed for the AFFECTIVE PROSODY subtests. PD patients in the more advanced stage were especially impaired in recognizing angry and frightened (and to a lesser extent happy) intonations. The common acoustic feature of these emotions is high mean pitch which is related to the speaker's arousal [60]. It is therefore possible that the PD-II patients present with a failure to process vocal cues of arousal, an issue that warrants attention in future 
studies. Since our design did not include the category disgust, our findings in patients with PD cannot directly be compared to those reported in patients with HD [65]. Similarly to patients with HD, the PD-II patients achieved the lowest scores for frightened and happy vocal emotions, but those were also the two most difficult categories for our HC. In summary, our findings do not provide clear evidence for an especially severe deficit for one particular emotion in PD.

As patients and $\mathrm{HC}$ did not significantly differ from each other in any of the NEUROPSYCHOLOGICAL background or MOOD variables and patients with lasting visual neglect were excluded (see [51]), the observed differences between the groups in the emotional tasks can neither be explained with general attentional or intellectual impairments, nor with mood changes in the patient groups.

SUMMARIZING the results for all clinical groups, patients in more advanced stages of PD showed the same general pattern of impairment as the patients with (right) anterior cortical lesions. The assumption of an important contribution of the fronto-striatal circuitry in emotional, especially in affective prosodic functions (e.g., [18]) is supported by the present data, and the observed deficits are also consistent with those of Scott et al. [62] and Pell [50] in patients in (presumably) more advanced stages of PD. A predominantly unilateral involvement of the basal ganglia (PD-I patients), however, exerted a weaker effect on patients' performance in emotional processing.

Alexander et al. [5] described two parallel prefrontal loops: the so-called 'dorsolateral prefrontal' circuit, which is associated with spatial memory and executive functions [44], and the 'lateral orbitofrontal' circuit, which receives input from both auditory and visual association areas of the temporal lobe and which contributes to cognitive and emotional functions [20]. A third basal ganglia loop, the 'limbic' circuit, receives input from the amygdala (e.g., via the ventral striatum, linking medial temporal lobe structures to orbitofrontal regions) and is considered to contribute to affective/motivational processes and divided attention. A contribution of these basal ganglia loops, particularly the 'LATERAL ORBITOFRONTAL' circuit with its involvement in emotion-related learning and social behavior [36, 44, 54, 55], could explain the present finding that predominantly patients with anterior cortical lesions as well as patients with more advanced PD presented overall with the strongest deficits in the processing of emotional stimulus material. The present study therefore provided further evidence for an in- volvement of the fronto-striatal circuitry in emotional functions $[40,75]$.

Unfortunately, the present investigation was planned and carried out before reports on disgust-specific deficits were reported in HD gene carriers [29] and our stimulus material did not include the emotional category disgust. Future studies with PD patients should therefore address the issue of 'the importance of the basal ganglia in the emotion of disgust' [29, p. 2036]. A further issue should be to examine the possible association of emotional processing and other neuropsychological functions [27].

\section{Acknowledgements}

We gratefully acknowledge the assistance of Dr. Stuart Brody for helpful discussion of many points and Laura Helmuth for her language assistance. We thank Dr. Dawn Bowers for allowing us to use her facial expression material.

\section{References}

[1] H. Ackermann, I. Hertrich and W. Ziegler, Prosodische Störungen bei neurologischen Erkrankungen - eine Literaturübersicht [Disturbances of speech prosody in neurological disease - a review], Fortschritte der Neurologie - Psychiatrie 61 (1993), 241-253.

[2] R. Adolphs, D. Tranel, H. Damasio and A. Damasio, Impaired recognition of emotion in facial expressions following bilateral damage to the human amygdala, Nature 372 (1994), 669-672.

[3] R. Adolphs, D. Tranel, H. Damasio and A.R. Damasio, Fear and the human amygdala, Journal of Neuroscience 15 (1995), 5879-5891.

[4] R. Adolphs, H. Damasio, D. Tranel, and A.R. Damasio, Cortical systems for the recognition of emotion in facial expressions, Journal of Neuroscience 16 (1996), 7678-7687.

[5] G.E. Alexander, M.D. Crutcher and M.R. DeLong, Basal ganglia-thalamocortical circuits: Parallel substrates for motor, oculomotor, 'prefrontal' and 'limbic' functions, Progress in Brain Research 85 (1990), 119-146.

[6] H. Barbas, Anatomic organization of basoventral and mediodorsal visual recipient prefrontal regions in the rhesus monkey, Journal of comparative Neurology 276 (1988), 313342.

[7] L.X. Blonder, D. Bowers and K.M. Heilman, The role of the right hemispere in emotional communication, Brain 114 (1991), 1115-1127.

[8] L.X. Blonder, R.E. Gur and R.C. Gur, The effects of right and left hemiparkinsonism on prosody, Brain and Language 36 (1989), 193-207.

[9] A. Bond and M. Lader, The use of analogue scales in rating subjective feelings, British Journal of Medical Psychology 47 (1974), 211-218. 
[10] J.C. Borod, Interhemispheric and intrahemispheric control of emotion: a focus on unilateral brain damage, Journal of Consulting and Clinical Psychology 60 (1992), 339-348.

[11] D. Bowers, R.M. Bauer, H.B. Coslett and K.M. Heilman, Processing of faces by patients with unilateral hemisphere lesions, Brain and Cognition 4 (1985), 258-272.

[12] D. Bowers, L.X. Blonder and K.M. Heilman, The Florida Affect Battery - Manual. Unpublished manuscript at the Center for Neuropsychological Studies, University of Florida, Gainesville, FL, USA.

[13] D. Bowers, L.X. Blonder, B. Slomine and K.M. Heilman, Nonverbal affect signals: patterns of impairment following hemispheric strokes using the Florida Affect Battery. Paper presented at the Annual Meeting of the American Psychological Society, San Franscisco, CA, USA.

[14] D. Bower and K.M. Heilman, Dissociation between the processing of affective and non-affective faces: a case study, Journal of Clinical Neuropsychology 4 (1984), 367-379.

[15] B. Bradvik, C. Dravins, S. Holtas, I. Rosen, E. Ryding and D.H. Ingvar, Do single right hemisphere infarcts or transient ischaemic attacks result in aprosody?, Acta Neurologica Scandinavica 81 (1990), 61-70.

[16] C. Breitenstein, I. Daum, H. Ackermann, R. Luetgehetmann and E. Mueller, Erfassung der Emotionswahrnehmung bei zentralnervoesen Laesionen und Erkrankungen: Psychometrische Guetekriterien der 'Tübinger Affekt Batterie' [Assessment of deficits in emotional perception following cortical and subcortical brain damage: psychometric properties of the 'Tübingen Affect Battery'], Neurologie \& Rehabilitation 2 (1996), 93-101.

[17] A.J. Calder, A.W. Young, D. Rowland, D.I. Perrett, J.R. Hodges and N.L. Etcoff, Facial emotion recognition after bilateral amygdala damage: differentially severe impairment of fear, Cognitive Neuropsychology 13 (1996), 699-745.

[18] A.E.B. Cancelliere and A. Kertesz, Lesion localization in acquired deficits of emotional expression and comprehension, Brain and Cognition 13 (1990), 133-147.

[19] M.J. Cohen, C.A. Riccio and A.M. Flannery, Expressive aprosodia following stroke to the right basal ganglia: a case report, Neuropsychology 8 (1994), 242-245.

[20] B. Crosson, Subcortical functions in language and memory, Guilford Press, New York, 1992.

[21] G. Dahl, Reduzierter Wechsler-Intelligenztest (WIP) [Short version of the Wechsler Scale], Hain, Meisenheim, 1972.

[22] I. Daum, H. Ackermann, M.M. Schugens, C. Reimold, J. Dichgans and N. Birbaumer, The cerebellum and cognitive functions in humans, Behavioral Neuroscience 107 (1993), 411-419.

[23] S.T. DeKosky, K.M. Heilman, D. Bowers and E. Valenstein, Recognition and discrimination of emotional faces and pictures, Brain and Language 9 (1980), 206-214.

[24] G. Denes, E.M. Caldognetto, C. Semenza, K. Vagges and M. Zettin, Discrimination and identification of emotions in human voice by brain-damaged subjects, Acta Neurologica Scandinavica 69 (1984), 154-162.

[25] N.L. Etcoff, Selective attention to facial identity and facial emotion, Neuropsychologia 22 (1984), 281-295.

[26] G. Gainotti, The meaning of emotional disturbances resulting from unilateral brain injury, in: Emotions and the dual brain, G. Gainotti and C. Caltagirone, eds, Springer, Heidelberg, 1989, pp. 173-202.

[27] M.S. George, P.I. Parekh, N. Rosinsky, T.A. Ketter, T.A. Kimbrell, K.M. Heilman, P. Herscovitch and R.M. Post, Un- derstanding emotional prosody activates right hemisphere regions, Archives of Neurology 53 (1996), 665-670.

[28] H. Goodglass and E. Kaplan, The assessment of aphasia and related disorders, Lea and Febinger, Philadelphia, 1983.

[29] J.M. Gray, A.W. Young, W.A. Barker, A. Curtis and D. Gibson, Impaired recognition of disgust in Huntington's disease gene carriers, Brain 120 (1997), 2029-2038.

[30] S.B. Hamann, L. Stefanacci, L.R. Squire, R. Adolphs, D. Tranel, H. Damasio and A. Damasio, Recognizing facial emotion, Nature 379 (1996), 497.

[31] K.M. Heilman, D. Bowers, L. Speedie and H.B. Coslett, Comprehension of affective and nonaffective prosody, $\mathrm{Neu}$ rology 34 (1984), 917-921.

[32] K.M. Heilman, D. Bowers and E. Valenstein, Emotional disorders associated with neurological diseases, in: Clinical Neuropsychology, K.M. Heilman and E. Valenstein, eds, Oxford University Press, New York, NY, 1993, pp. 461-497.

[33] K.M. Heilman, R. Scholes and R.T. Watson, Auditory affective agnosia: disturbed comprehension of affective speech, Journal of Neurology, Neurosurgery, and Psychiatry 38 (1975), 69-72.

[34] L. Heimer, R.D. Switzer and Van G.W. Hoesen, Ventral striatum and ventral pallidum - Components of the motor system?, Trends in Neurosciences 5 (1982), 83-87.

[35] M.M. Hoehn and M.D. Yahr, Parkinsonism: onset, progression, and mortality, Neurology 17 (1967), 427-442.

[36] J. Hornak, E.T. Rolls and D. Wade, Face and voice expression identification in patients with emotional and behavioral changes following ventral frontal lobe damage, Neuropsychologia 34 (1996), 247-261.

[37] D.H. Jacobs, J. Shuren, D. Bowers and K.M. Heilman, Emotional facial imagery, perception, and expression in Parkinson's disease, Neurology 45 (1995), 1696-1702.

[38] A.E. Kelley, V.B. Domesick and W.J.H. Nauta, The amygdalostriatal projection in the rat - an anatomical study by anterograde and retrograde tracing methods, Neuroscience 7 (1982), 615-630.

[39] K.S. LaBar, J.E. LeDoux, D.E. Spencer and E.A. Phelps, Impaired fear conditioning following unilateral temporal lobectomy in humans, Journal of Neuroscience 15 (1995), 68466855 .

[40] S. Lalande, C.M.J. Braun, N. Charlebois and H.A. Whitaker, Effects of right and left hemisphere cerebrovascular lesions on discrimination of prosodic and semantic aspects of affect in sentences, Brain and Language 42 (1992), 165-186.

[41] J.E. LeDoux, Emotion: Clues from the brain, Annual Review of Psychology 46 (1995), 209-235.

[42] R. Ley and M. Bryden, Hemispheric differences in recognizing faces and emotions, Brain and Language 7 (1979), 127-138.

[43] R. Ley and M. Bryden, A dissociation of right and left hemsiphere effects for recognizing emotional tone and verbal content, Brain and Cognition 1 (1982), 3-9.

[44] D.L. Masterman and J.L. Cummings, Frontal-subcortical circuits: the anatomic basis of executive, social, and motivated behaviors, Journal of Psychopharmacology 11 (1997), 107114.

[45] G.H. Monrad-Krohn, The prosodic quality of speech and its disorders, Acta Psychiatrica Neurologica Scandinavia 22 (1947), 255-269.

[46] R.J. Morecroft, C. Geula and M.-M. Mesulam, Cytoarchitecture and neural afferents of the orbito-frontal cortex in the brain of the monkey, Journal of comparative Neurology $\mathbf{3 2 3}$ (1992), 341-358. 
[47] J.S. Morris, C.D. Frith, D.I. Perrett, D. Rowland, A.W. Young, A.J. Calder and R.J. Dolan, A differential neural response in the human amygdala to fearful and happy facial expressions, Nature 383 (1996), 812-815.

[48] R.C. Oldfield, The assessment and analysis of handedness: the Edinburgh Inventory, Neuropsychologia 9 (1971), 97113.

[49] A.M. Owen, M. James, P.N. Leigh, B.A. Summers, C.D. Marsden, N.P. Quinn, K.W. Lange and T.W. Robbins, Frontostriatal cognitive deficits at different stages of Parkinson's disease, Brain 115 (1992), 1727-1751.

[50] M.D. Pell, On the receptive prosodic loss in Parkinson's disease, Cortex 32 (1996), 693-704.

[51] M.D. Pell and S.R. Baum, The ability to perceive and comprehend intonation in linguistic and affective contexts by braindamaged adults, Brain and Language 57 (1997), 80-99.

[52] I. Peretz, R. Kolinsky, M. Tramo, R. Labrecque, C. Hublet, G. Demeurisse and S. Belleville, Functional dissociations following bilateral lesions of auditory cortex, Brain 117 (1994), 1283-1301.

[53] M.L. Phillips, A.W. Young, C. Senior, M. Brammer, C. Andrew, A.J. Calder, E.T. Bullmore, D.I. Perrett, D. Rowland, S.C.R. Williams, J.A. Gray and A.S. David, A specific neural substrate for perceiving facial expressions of disgust, $\mathrm{Na}$ ture 389 (1997), 495-498.

[54] E.T. Rolls, A theory of emotion, and its application to understanding the neural basis of emotion, Cognition and Emotion 4 (1990), 161-190.

[55] E.T. Rolls, J. Hornak, D. Wade and J. McGrath, Emotionrelated learning in patients with social and emotional changes associated with frontal lobe damage, Journal of Neurology Neurorsurgery, and Psychiatry 57 (1994), 1518-1524.

[56] E.D. Ross, The Aprosodias. Functional-anatomic organization of the affective components of language in the right hemisphere, Archives of Neurology 38 (1981), 561-569.

[57] E.D. Ross and M.-M. Mesulam, Dominant language functions of the right hemisphere? Prosody and emotional gesturing, Archives of Neurology 36 (1979), 144-148.

[58] E.D. Ross, R.D. Thompson and J. Yenkosky, Lateralization of affective prosody in brain and the callosal integration of hemispheric language functions, Brain and Language 56 (1997), $27-54$.

[59] K.R. Scherer, How emotion is expressed in speech and singing. Proceedings of the XIIIth International Phonetic Sciences, Stockholm, Sweden, August 1995 (Vol. 3, S. 90-96).

[60] K.R. Scherer and J.S. Oshinsky, Cue utilization in emotion attribution from auditory stimuli, Motivation and Emotion 4 (1977), 331-346.

[61] J.J. Schmitt, W. Hartje and K. Willmes, Hemispheric asymmetry in the recognition of emotional attitude conveyed by facial expression, prosody, and propositional speech, Cortex 33 (1997), 65-81.
[62] S. Scott, F.I. Caird and B. Williams, Evidence for an apparent sensory speech disorder in Parkinson's disease, Journal of Neurology, Neurosurgery, and Psychiatry 47 (1984), 840483.

[63] S.K. Scott, A.W. Young, A.J. Calder, D.J. Hellawell, J.P. Aggleton and M. Johnson, Impaired auditory recognition of fear and anger following bilateral amygdala lesions, Nature $\mathbf{3 8 5}$ (1997), 254-257.

[64] E. Silberman and H. Weingartner, Hemispheric lateralization of functions related to emotions, Brain and Cognition 5 (1986), 322-353.

[65] R. Sprengelmeyer, A.W. Young, A.J. Calder, A. Karnat, H. Lange, V. Hoemberg, D.I. Perrett and D. Rowland, Loss of disgust - Perception of faces and emotions in Huntington's disease, Brain 119 (1996), 1647-1665.

[66] S.E. Starkstein, J.P. Federoff, T.R. Price, R.C. Leiguarda and R.G. Robinson, Neuropsychological and neuroradiologic correlates of emotional prosody comprehension, Neurology 44 (1994), 515-522.

[67] V.E. Stone, L. Nisenson, J.C. Eliassen and M.S. Gazzaniga, Left hemisphere representations of emotional facial expressions, Neuropsychologia 34 (1996), 23-29.

[68] C.A. Tompkins and C.R. Flowers, Perception of emotional intonation by brain-damaged adults: the influence of task processing levels, Journal of Speech and Hearing Research 28 (1985), 527-538.

[69] D. Tucker, R.T. Watson and K.M. Heilman, Discrimination and evocation of affectively intoned speech in patients with right parietal disease, Neurology 27 (1977), 947-950.

[70] D. Van Lancker and J. Kreiman, Voice discrimination and recognition are separate abilities, Neuropsychologia $\mathbf{2 5}$ (1987), 829-834.

[71] D. Van Lancker, J. Kreiman and J. Cummings, Voice perception deficits: Neuroanatomical correlates of phonagnosia, Journal of Clinical and Experimental Neuropsychology 11 (1989), 665-674.

[72] D. Van Lancker and J.J. Sidtis, The identification of affectiveprosodic stimuli by left- and right-hemisphere-damaged subjects: all errors are not created equal, Journal of Speech and Hearing Research 35 (1992), 963-970.

[73] D.A. Wechsler, Wechsler Adult Intelligence Scale - Revised, The Psychological Corporation, New York, NY, 1981.

[74] R.A. Weddell, Recognition memory for emotional facial expressions in patients with focal cerebral lesions, Brain and Cognition 11 (1989), 1-17.

[75] R.A. Weddell, Effects of subcortical lesion site on human emotional behavior, Brain and Cognition 25 (1994), 161193.

[76] A.W. Young, D.J. Hellawell, C. Van de Wal and M. Johnson, Facial expression processing after amygdalotomy, Neuropsychologia 34 (1996), 31-39. 


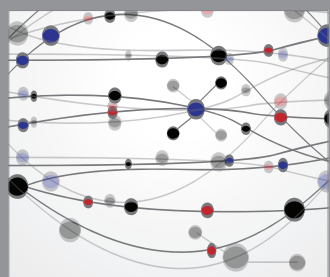

The Scientific World Journal
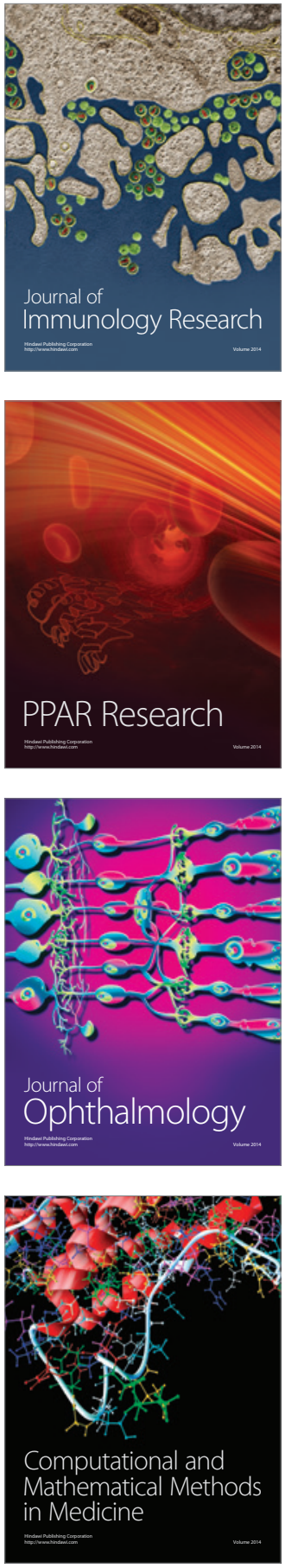

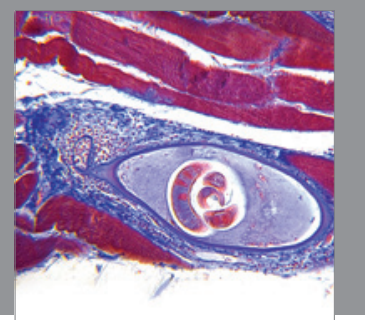

Gastroenterology

Research and Practice
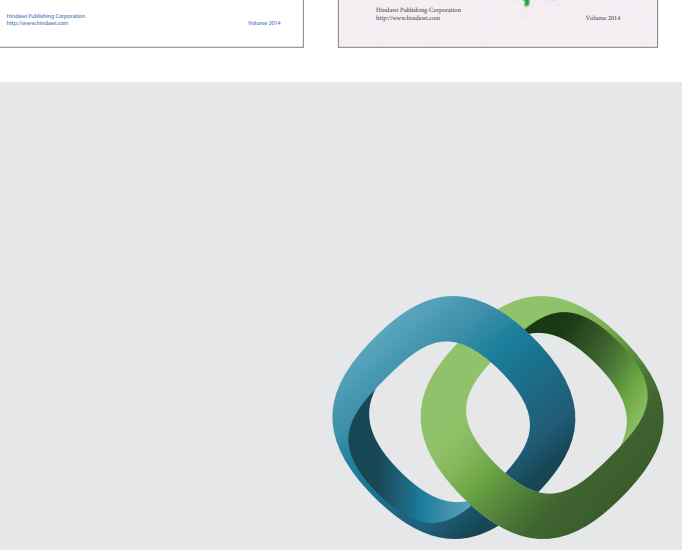

\section{Hindawi}

Submit your manuscripts at

http://www.hindawi.com
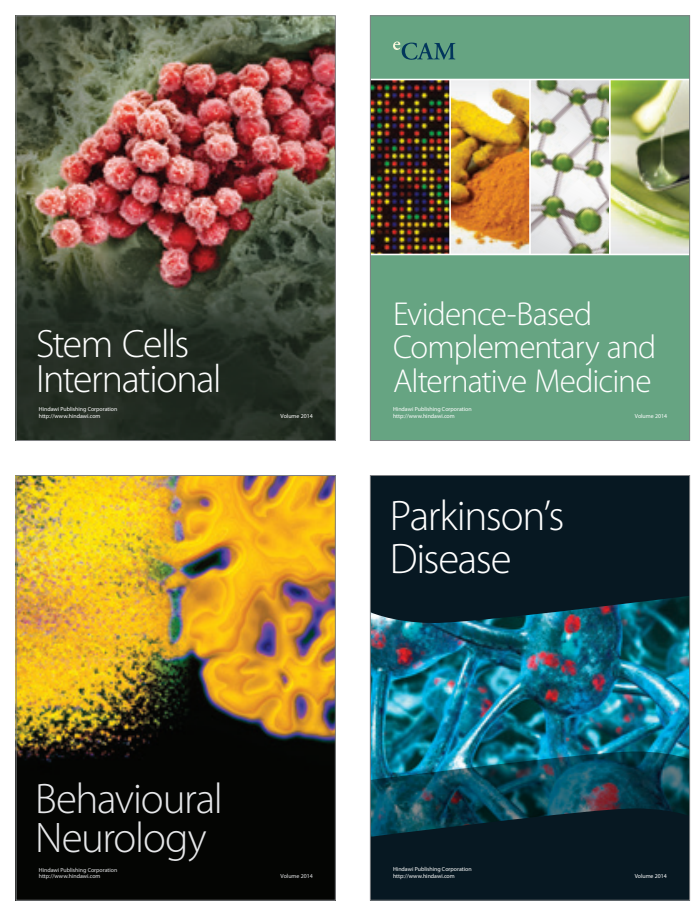

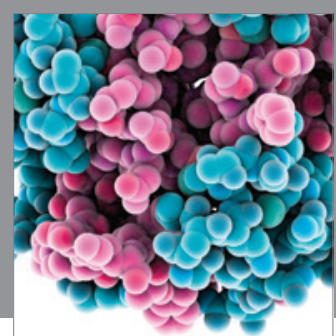

Journal of
Diabetes Research

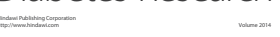

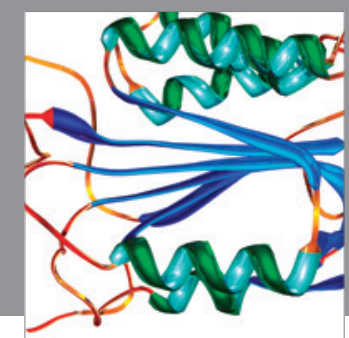

Disease Markers
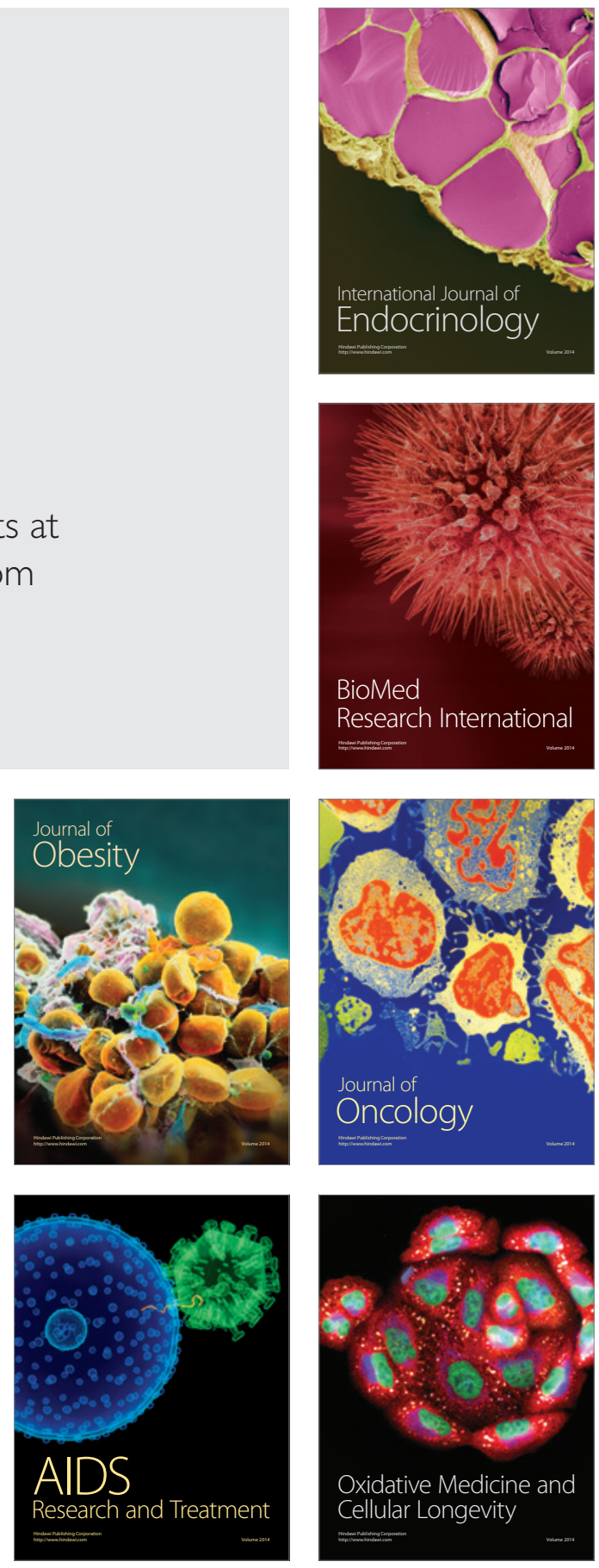